Revista Internacional Educon | ISSN 2675-672

Volume 2, n. 1, e20011023, jan./mar. 2021

https:/ / doi.org/ 10.47764/e20011023

\title{
Formação Docente em Serviço: um Espaço de Disputas e Resistências
}

\author{
In-service Teacher Training: a Space for Disputes and Resistance \\ Formación de Profesores en Servicio: un Espacio de Disputas e \\ Resistencias
}

ELISABETE FERREIRA ESTEVES CAMPOS

Universidade Metodista de São Paulo

RESUMO: Para a implementação da Base Nacional Comum Curricular-BNCC, um município da Grande São Paulo tem realizado formações em serviço visando à adequação de currículos e práticas de ensino. Considerando o caráter tecnicista e regulatório da BNCC, analisamos os planos de formação docente de oito escolas públicas de período integral localizadas nesse município, com o objetivo de verificar se, no bojo dessa política regulatória, há espaço para uma contrarregulaşão, mantendo os fundamentos da educação integral. Por meio da análise documental consideramos, com base na epistemologia do ciclo de políticas que, no contexto da prática, as politicas não são simplesmente implementadas. Com os fundamentos de Freire, concluimos que a formação em serviço é um espaço de disputas e resistências e as equipes escolares, apesar de estarem submetidas às diretrizes impostas, podem assumir princípios éticos e democráticos, com pressupostos epistemológicos humanistas e emancipatórios.

FORMAÇÃO DOCENTE. BASE NACIONAL COMUM CURRICULAR. EDUCAÇÃO INTEGRAL. PAULO FREIRE.

\begin{abstract}
To implement the Base Nacional Comum Curricular-BNCC (National Common Curricular Base) in Brazilian schools, a municipality in São Paulo carried out a teachers' training program to adapt curricula and teaching practices. Considering the technical and regulatory nature of the BNCC, we analyzed the teachers' training plans of eight full-time public schools aiming at verifying whether, within the scope of this regulatory policy, there is a path towards counter-regulation, with the foundations of integral education. Through document analysis and based on the policy cycle epistemology, we consider that in the context of practice, policies are not simply implemented. Our analyses, based on Freire, indicated that inservice training is a space of dispute and resistance. Although school teams are subject to the imposed guidelines, they can assume ethical and democratic positions, with humanist and emancipatory epistemological supports.

TEACHING TRAINING. NATIONAL COMMON CURRICULAR BASE. INTEGRAL EDUCATION. PAULO FREIRE.
\end{abstract}

A autora cede à Revista Internacional Educon os direitos de primeira publicação do presente artigo. Aplicam-se os termos de uma licença Creative Commons Atribuição 4.0 Internacional (CC BY 4.0), que permite o uso irrestrito, a distribuição e a reprodução em qualquer meio desde que a publicação original seja corretamente citada. 
RESUMEN: Para implementar la Base Curricular Común Nacional en las escuelas brasileñas, un município del Gran São Paulo propuso la capacitación en servicio, para adaptar los currículos y las práticas docentes. Considerando el caráter técnico y regulatorio del BNCC, analizamos los planes de formación docente de ocho esculas públicas de tiempo completo, con el objetivo de verificar si, en el ámbito de esta politica regulatoria, hay espacio para la contrarregulación, manteniendo los fundamentos de la educación emancipadora integral. A través del análisis documental, consideramos, con base en la epistemología del ciclo de políticas, que en el contexto de la práctica las politicas no se implementan simplesmente. Nuestros análisis, basados en Freire, indicaron que la formación en servicio es un espacio de disputas y resistencias. Al mismo tiempo que los docentes están sujetos a las pautas impuestas, pueden assumir posiciones y princípios éticos y democráticos, con supuestos epistemológicos bumanistas y emancipatórios.

\section{ENSEÑANZA ENTRENAMIENTO. BASE CURRICULAR COMÚN NACIONAL. EDUCACIÓN INTEGRAL. PAULO FREIRE.}

\section{Introdução}

Desenvolvemos pesquisas enquanto o mundo enfrenta uma terrível pandemia provocada pela COVID-19, desencadeando, no Brasil, o aumento do desemprego, da pobreza e ampliando as desigualdades. São incontestáveis os prejuízos para os estudantes das áreas empobrecidas que enfrentam obstáculos com as aulas remotas, seja pela carência de equipamentos tecnológicos e internet, pela dificuldade de acesso a materiais didáticos ou mesmo pela falta de estrutura doméstica para os estudos. A tese neoliberal, no entanto, considera a desigualdade como um efeito colateral, que vai se naturalizando. Com as mudanças nas relações sociais requeridas para conter a expansão do vírus, o discurso de um "novo normal" se estabelece, desconsiderando que já antes da pandemia não vivíamos em um mundo "normal".

Não se pode considerar normal a situação de um país que, antes da pandemia, tinha $51,2 \%$ da população acima de 25 anos sem a educação escolar básica completa (Agência IBGE, 2020). Da mesma forma, não é normal que mais de 2 milhões de crianças e adolescentes de 5 a 17 anos estejam em situação de trabalho infantil, sendo $64,1 \%$ de negros. Dados como esses indicam claramente que o acesso à escola é restrito.

O Brasil ainda não conseguiu universalizar a educação básica, nem atingir as metas estabelecidas no Plano Nacional de Educação (PNE) para o período de 2014 a 2024, conforme balanço publicado pela Campanha Nacional pelo Direito à Educação.

O PNE não está sendo cumprido. No lugar dele, são colocadas uma série de políticas públicas que vão na contramão do que ele preconiza: políticas discriminatórias, excludentes, de censura, e de esvaziamento da escola como lugar vivo, democrático, transformador e livre. Assim, o descumprimento do Plano Nacional de Educação está no centro da barbárie que toma a educação nacional (Campanha Nacional pelo Direito à Educação, 2020, p. 55).

Nesse cenário de abandono, a educação segue com programas que reafirmam a política de padronização e regulação com a Base Nacional Comum Curricular - BNCC, documento de caráter normativo que definiu um "conjunto de aprendizagens essenciais", indicando "conhecimentos e competências que se espera que todos os estudantes desenvolvam ao longo da escolaridade" (Brasil, 2017, p. 7).

Esse documento, organizando um conjunto de unidades temáticas, objetivos e habilidades definidas para cada ano escolar em todo o País, apresenta a narrativa da educação integral, mas distorcendo esse conceito com a lógica da padronização e fragmentação das disciplinas. Sem conceber que a educação integral requer a necessária "inserção crítica" (Freire, 2001, 2005) dos estudantes na realidade, ficam intocadas as problematizações das questões sociais e das necessárias políticas públicas 
para garantia dos direitos constitucionais a todos os brasileiros e brasileiras, prevalecendo um modelo curricular que se aproxima de uma educação tecnicista.

Para a implementação da BNCC em todas as escolas do País, as redes de ensino foram orientadas a realizar formações para os docentes com o propósito de adequar currículos e práticas de ensino, desconsiderando políticas de educação integral que vinham sendo propostas por governos anteriores, conforme destacamos no Programa Mais Educação, iniciado em 2010.

Assim, podemos dizer que o Programa Mais Educação propõe pensarmos e praticarmos a Educação Integral a partir da articulação educação-território, considerando a formação dos sujeitos da educação como inseparável das relações e transformações ocorridas no ambiente, a partir do entendimento do caráter territorial dos processos educacionais na escola e na cidade, sem que se perca o protagonismo da escola (Brasil, 2014, p. 18).

É fato que, em nosso país, a descontinuidade das políticas vem se perpetuando, uma vez que não são formuladas com a ampla participação da sociedade e dos docentes, considerados apenas como executores e implementadores das políticas definidas em instâncias superiores. E a Escola, "enquanto instituição social, assume diferentes significados para as ideologias que se cruzam nas sociedades" (Benavente, 2011, p. 1). A cada novo governo, novas diretrizes.

Por outro lado, os docentes, em seu processo de profissionalização, apoiados pela produção acadêmica, pela luta das entidades representativas, pela reflexão coletiva nos espaços escolares, ao se depararem com diferentes políticas, podem assumir posicionamentos críticos, reinterpretando e recriando as políticas.

É nesse contexto que apresentamos, neste artigo, nossas análises dos planos de formação docente de oito escolas públicas de um município da Grande São Paulo, que atendem alunos em período integral, na perspectiva da educação integral. Os planos de formação foram analisados com o objetivo de verificar se, no bojo dessa política regulatória, há espaço para uma contrarregulação, mantendo, nos documentos, os fundamentos da educação integral crítica e emancipatória.

Com a epistemologia do ciclo de políticas elaborada por Ball, Maguire e Braun (2016), entende-se que as políticas não são simplesmente implementadas. No contexto da prática, há possibilidades de reinterpretação e recriação, especialmente ao considerar que a prática educativa é histórica, e os docentes têm um percurso formativo pessoal e profissional que não permite a simples execução de programas e políticas.

Trata-se de pesquisa documental, analisando as vozes das equipes docentes nos documentos escritos (Lüdke \& André, 2015). Para Freire (2001, p. 36), a "impossibilidade da neutralidade da educação" implica em identificar o posicionamento dos educadores e as opções assumidas. Quando assumem "uma opção democrática", rejeitam a compreensão da educação como "ato mecânico de transferir" "pacotes prontos de conhecimentos" (Freire, 2001, p. 36). O educador democrático recusa a "visão estreita da escola como um espaço exclusivo de lições de ensinar e de lições a tomar", compreendendo, entretanto, que a escola não está imune "das lutas, dos conflitos, que se dão longe dela, no mundo distante" (Freire, 2001, p. 36). Com os fundamentos da educação crítica e emancipadora de Freire, apresentamos as análises dos planos de formação docente em oito escolas públicas de educação básica. 


\section{A Base Nacional Comum Curricular: contradições e ressignificações}

Em 2017, após um processo conturbado que levou ao impeachment da presidenta Dilma Rousseff, a Base Nacional Comum Curricular - BNCC (Brasil, 2017) foi publicada com alterações realizadas pela nova equipe que assumiu o Ministério da Educação.

A BNCC foi amplamente criticada por entidades educacionais que identificaram retrocessos nessa política, especialmente na última versão, publicada como documento legal a ser implementado em todas as escolas do País. As manifestações contrárias ressaltaram o caráter antidemocrático dessa política, que privilegiou interesses mercadológicos (Associação Nacional pela Formação dos Profissionais da Educação [Anfope], 2017).

A nota pública da Associação Nacional de Pós-Graduação e Pesquisa em Educação (Anped, 2017) considera que a BNCC foi inspirada em modelos de centralização curricular, tais como o "Common Core Americano, o Currículo Nacional desenvolvido na Austrália, e a reforma curricular chilena - todas essas experiências amplamente criticadas em diversos estudos realizados sobre tais mudanças em cada um desses países".

No documento da BNCC, identificamos contradições difíceis de superar, uma vez que podem levar a uma interpretação enganosa, encobrindo seus reais propósitos. Os termos "educação integral" e "formação integral" são mencionados em uma aparente abordagem progressista, mas uma análise cuidadosa indica que tais termos são ressignificados ao apresentar uma lista de competências e habilidades a serem desenvolvidas em cada ano e em cada disciplina.

Divergindo da BNCC organizada por ano de escolaridade, a concepção progressista e democrática considera que a educação integral tem como um de seus pilares a superação da fragmentação disciplinar, o que é outro ponto de retrocesso no documento.

Muitas escolas, no Brasil, já assumiram os ciclos na educação básica (Mainardes, 2006), agrupando estudantes em função das etapas de desenvolvimento. Essa opção, prevista na Lei de Diretrizes e Bases (Brasil, 1996), não foi respeitada no documento, que estabelece um rol de habilidades específicas em cada disciplina de acordo com o ano de escolaridade, opondo-se ao conceito de ciclos. Um código identificando cada habilidade demonstra uma prática tecnicista para facilitar a avaliação, cuja padronização está a serviço de um mecanismo de controle em flagrante dissonância com a narrativa da educação integral.

A relação com o território, outro pressuposto da educação integral, não é assumida na BNCC. O texto do documento se alinha à tese neoliberal, aproximando a educação da lógica empresarial, que não tem o propósito de compreender e transformar a realidade. Não reconhece as Cidades como "educadoras e educandas", com todas as suas contradições (Gadotti, 2009). Desconsidera que "a Cidade somos nós também, nossa cultura, que, gestando-se nela, no corpo de suas tradições, nos faz e nos refaz. Perfilamos a Cidade e por ela somos perfilados" (Freire, 2001, p. 14), por isso, a memória da Cidade, "seus museus, seus centros de cultura, de arte são a alma viva do ímpeto criador, dos sinais de aventura do espírito. Falam de épocas diferentes, de apogeu, de decência, de crises" (Freire, 2001, p. 14). E falam também da indecência, da produção de desigualdades e de injustiças. Assim, a educação na perspectiva da formação integral é indissociável da relação com a Cidade.

Muito de sua tarefa educativa implica a nossa posição política e, obviamente, a maneira como exerçamos o poder na Cidade e o sonho ou a utopia de que embebamos a política, a serviço de que e de quem a fazemos. A política dos gastos públicos, a política cultural e educacional, a política de saúde, a dos transportes, a do lazer (Freire, 2001, p. 13).

As habilidades definidas na BNCC não pressupõem a relação entre conteúdo e análise crítica e problematizadora da realidade e das políticas. Em muitas cidades brasileiras, o atendimento à saúde é precário, a população não tem acesso adequado à água tratada e saneamento básico, situação que é ignorada no rol de temas e habilidades. $\mathrm{Na}$ Base, há intenção de ensinar aos estudantes a importância do 
uso consciente da água, sem nenhuma relação com a falta de políticas públicas que mantêm populações desassistidas, causando doenças e desrespeitando os direitos fundamentais das pessoas. A educação integral preconizada não é emancipadora.

Nesse documento, foram apagados conceitos e temáticas relevantes à educação integral que vinham sendo assumidos nos currículos escolares de muitas escolas. Sobre essa questão, assim se posicionou o Fórum Nacional de Educação:

\begin{abstract}
O posicionamento do MEC, ao suprimir conceitos e temáticas fundamentais para a promoção dos direitos humanos e valorização das diversidades, em um país marcado pelo machismo, pela homofobia e a misoginia, ignora o fato de que nas instituições educativas e fora delas pessoas são marginalizadas e vítimas de preconceito e violência e, por consequência, abandonam a vida escolar e/ou têm tolhidas inúmeras oportunidades de vida (Fórum Nacional de Educação, 2017, p. 2).
\end{abstract}

Identifica-se, na BNCC, que não há intenção de formar cidadãos participativos que assumam uma "práxis transformadora" (Freire, 2005, p. 46) visando ao fortalecimento de uma sociedade menos desigual, superando os preconceitos e racismos que são estruturais em nosso país. A expectativa dessa política é somente que os estudantes construam competências para enfrentar a concorrência do mercado, no modelo de uma educação credencialista (Arroyo, 2000).

A educação vem sendo cooptada pela lógica empresarial para a formação de trabalhadores competentes, com a presença dos "reformadores empresariais na educação" (Freitas, 2012), e essa lógica se explicita também nas diretrizes para a formação docente, que discutiremos a seguir.

\title{
2 A BNCC na formação docente
}

Para a implementação da BNCC iniciou-se, em 2018, a promoção de eventos, e proliferaram cursos à distância para os docentes com uma formação padronizada, em um modelo que não reconhece o trabalho docente como princípio educativo e ação humanizadora (Frigoto, 1985), tampouco seu caráter social e histórico na produção do conhecimento (Freire, 2001). A compreensão dos docentes como implementadores de políticas se perpetua.

Em 2019, o MEC publicou a versão preliminar das Diretrizes Curriculares Nacionais e Base Nacional Comum para a Formação Inicial e Continuada de Professores da Educação Básica, reafirmando o propósito de "fundamentar a concepção, formulação, implementação, avaliação e revisão dos currículos e das propostas pedagógicas" de todas as escolas do País, em consonância com a BNCC, por meio de uma coordenação nacional, para "o devido alinhamento das políticas e ações educacionais, especialmente a política para formação inicial e continuada de professores” (Brasil, 2019, p. 1).

O documento publicado promove uma formação utilitarista, pressupondo a prática docente para desenvolver competências nas crianças, adolescentes, jovens e adultos, com o propósito de obterem melhores condições de "empregabilidade e outras variáveis ligadas ao bem-estar da pessoa, como a saúde e os relacionamentos interpessoais" (Brasil, 2019, p. 16). Como se dependesse apenas das pessoas, individualmente, o seu sucesso ou fracasso.

A ausência de problematização dessa política na formação docente imprime a crença em uma educação "manhosamente" (Freire, 2001) neutra, que mantém o discurso da educação integral para evitar críticas aos pressupostos capitalistas e reforçar o seu poder hegemônico. Na formação docente, obstaculizam a compreensão da realidade opressora e desigual, não permitindo a "inserção crítica" (Freire, 2001, 2005) dos docentes, com o falso argumento da educação sem ideologia propagada pelos ultraconservadores.

Nessa diretriz, a formação, alinhada à BNCC, está divorciada do território, não prevendo que os docentes conheçam a Cidade e o mundo dos estudantes: Onde vivem? Como se divertem? Que lugares 
frequentam? Há acesso à saúde, cultura, lazer? Estão garantidos os serviços básicos de saneamento, água, eletricidade em suas moradias?

Da mesma forma, não se propõe conhecer os docentes, seu percurso pessoal, profissional, formativo e seu cotidiano de trabalho: Como compreendem as finalidades da educação escolar? Com qual currículo? Com qual metodologia? Como realizam a avaliação dos estudantes? Como se dá a relação dos docentes com os estudantes e famílias? Há participação na gestão escolar? Quais são suas condições objetivas de trabalho?

O modelo de formação docente para a implementação da BNCC, de caráter tecnicista, está apartado da realidade social, escolar e dos próprios sujeitos, ficando a serviço de uma escola controladora, que exclui o pensamento crítico. Temos dados em abundância que demonstram a influência economicista na formulação dessa política educacional, com decisões centralizadas e autoritárias, concebendo as finalidades educativas para adaptação a uma sociedade regida pelas leis do livre mercado, tal como afirmam Maués (2009), Freitas (2012, 2013, 2014), Adrião et al. (2019), Libâneo (2019), dentre outros.

Com os fundamentos da epistemologia do ciclo de políticas (Ball et al., 2016), identifica-se que o contexto de formulação dessa política está sob a influência de grupos empresariais e grupos políticos com interesses próprios. As convicções ideológicas, filosóficas, religiosas e políticas dos grupos dominantes, compõem uma poderosa rede de influências, distanciando-se das finalidades humanistas da educação.

As justificativas para as políticas educacionais formuladas por tais grupos apresentam argumentos genéricos, como melhorar índices de desempenho nos exames padronizados, evitar a evasão, corrigir fluxo, sem a devida análise da complexidade e dos múltiplos fatores que interferem nos dados que oferecem. Refutando a necessidade de políticas em diferentes âmbitos, responsabilizam as equipes escolares pelos êxitos e fracassos na educação. Essa responsabilização é materializada com a oferta de cursos a partir dos quais os docentes devem mudar a sua prática.

Sem uma análise aprofundada da realidade social e educacional do País, as equipes escolares ficam à mercê dessas políticas que pretendem orientar e regular sua prática. A cada mudança de governo, novas reformas e pacotes chegam às escolas, pressupondo novas mudanças sob a responsabilidade das equipes escolares, levando a sociedade a culpá-las pelos fracassos e deficiências na educação de brasileiros e brasileiras.

Nesse cenário, analisamos os planos de formação de oito escolas públicas que atendem estudantes dos anos iniciais do ensino fundamental, no intuito de identificar, nesses planos, como se propõe a BNCC e se há indícios de resistência, mantendo os fundamentos da educação integral emancipadora, que pressupõe a criticidade, o olhar problematizador para a realidade e gradativa construção da consciência crítica (Freire, 2005).

Para Freire (1974, p. 8), a educação é um fenômeno humano que requer a compreensão das finalidades da educação em função da sociedade que se deseja.

Se, para uns, o homem [a mulher e todas as pessoas] é um ser de adaptação ao mundo (tomandose o mundo não apenas em sentido natural, mas estrutural, histórico-cultural), sua acção educativa, seus métodos, seus objectivos, adequar-se-ão a essa concepção. Se, para outros, o homem [a mulher e todas as pessoas] é um ser de transformação do mundo, seu quefazer educativo segue um outro caminho.

Se o professor e a professora se recusam a transformar os educandos em objetos por meio de uma ação mecanicista e autoritária; se reconhecem a "vocação ontológica" do "sujeito que opera e transforma o mundo" (Freire, 2005, p. 47); se assumem a educação como processo de ação-reflexão do mundo e com o mundo para a construção da gradativa consciência crítica (Freire, 1974, p. 16-17), não serão indiferentes às políticas e projetos que pretendem domesticar e adaptar docentes e educandos à realidade supostamente imutável.

Mas é imperativo reconhecer que as políticas neoliberais e as pautas neoconservadoras interferem na formação inicial, nas condições objetivas de trabalho dos profissionais da educação, provocam 
fragilidades em seu processo formativo, influenciam programas e diretrizes estabelecidas pela administração central e local, o que pode obstaculizar ou retardar a construção de sua "consciência crítica" (Freire, 2005).

Com tais ponderações, procedemos à análise dos planos de formação docente de oito escolas públicas de uma rede municipal da Grande São Paulo.

\section{Análise dos planos de formação}

As políticas educacionais, definindo diretrizes e metas, incidem sobre a organização das escolas de educação básica, interferindo no Projeto Político-Pedagógico e formação docente. Tais políticas desconsideram um diagnóstico da realidade social e educacional do País e toda a sua diversidade nos estados e municípios, sendo elaboradas por equipes de especialistas dos governos que assumem o poder central, imprimindo suas convicções políticas e ideológicas.

Em 2018, a rede municipal em questão iniciou a elaboração de um programa formativo para os profissionais de todas as suas escolas para a implementação da BNCC, levando à reformulação, no ano seguinte, dos planos de formação no âmbito das unidades escolares.

Com o propósito de verificar se no bojo dessa política regulatória há espaço para uma contrarregulação, mantendo os fundamentos da educação integral crítica e emancipatória, analisamos os planos de formação docente de oito escolas de uma rede municipal da Grande São Paulo que atendem estudantes em período integral na perspectiva da educação integral. Os documentos estão disponíveis na internet, o que atesta sua autenticidade e confiabilidade.

A abordagem qualitativa com base na análise documental (Lüdke \& André, 2015) se revelou apropriada nessa investigação, em função dos objetivos da pesquisa. A análise documental é especialmente indicada "Quando o interesse do pesquisador é estudar o problema a partir da própria expressão dos indivíduos, ou seja, quando a linguagem dos sujeitos é crucial para a investigação. Nessa situação incluem-se todas as formas de produção do sujeito em forma escrita" (Holsti, 1969 citado por Lüdke \& André, 2015, p. 46).

Os documentos constituem "fonte poderosa de onde podem ser retiradas evidências que fundamentam afirmações e declarações do pesquisador [...] surgem num determinado contexto e fornecem informações sobre esse mesmo contexto" (Lüdke \& André, 2015, p. 45).

Nesses termos, identificamos que os planos de formação docente são elaborados por indicação da Secretaria de Educação e inseridos nos Projetos Político-Pedagógicos que sofreram mudanças com a publicação da BNCC.

Ainda assim, contatamos que os Projeto Político-Pedagógicos mantiveram referências à formação integral dos estudantes, mencionando princípios considerados fundamentais, dos quais destacamos, conforme documentos: compreensão do ser humano em toda a sua inteireza; respeito e consideração da diversidade de saberes, culturas, valores e crenças dos educandos; integração dos conhecimentos; articulação entre as disciplinas e profissionais da escola; ampliação do tempo escolar como indicador de melhores oportunidades de aprendizado; diversificação dos espaços escolares e dos projetos didáticos; participação dos estudantes no planejamento escolar e nas tomadas de decisões.

Por meio da educação integral se reconhece, conforme consta nos documentos dessas escolas, as múltiplas dimensões do ser humano e a peculiaridade do trabalho pedagógico em função da faixa etária e dos diferentes agrupamentos. A partir desse entendimento, as equipes escolares estabelecem os objetivos e conteúdos, o que nos leva a considerar que a política da BNCC, a qual padroniza objetivos e temas, não está sendo simplesmente implementada, como preconiza a epistemologia do ciclo de políticas (Ball et al., 2016). Mas há diferentes níveis de elaboração.

$\mathrm{Na}$ apresentação das análises, para manter o sigilo em relação às unidades escolares, os documentos foram identificados como PF1, PF2, PF3, PF4, PF5, PF6, PF7 e PF8. Uma vez que os documentos são elaborados pela equipe escolar, seguindo orientações da Secretaria de Educação, foram encontrados em 
todos os planos os mesmos itens: tema, objetivos, conteúdos, ação formativa e cronograma. Constata-se que uma parte do horário de trabalho coletivo dos docentes em 2019 foi dedicada à formação preparada e coordenada pela Secretaria de Educação, para a implementação da BNCC. O planejamento do horário restante ficou sob a responsabilidade da equipe gestora, revelando, de início, uma formação fragmentada.

Após a leitura flutuante dos documentos, foram definidas categorias que emergiram do "arcabouço teórico em que se apoia a pesquisa" (Lüdke \& André, 2015, p. 50). Com base nos fundamentos de Freire, considera-se que a formação docente é um processo contínuo, permanente, visando à emancipação e à construção do pensamento crítico e autônomo. Trata-se da preparação de um profissional curioso, indagador, que compreende a relevância de seu papel social na educação de todos os estudantes, o que implica em conhecer os alunos e alunas, identificar seus saberes, sua cultura, crenças e valores, o lugar onde vivem e sonham.

Partindo do referencial teórico, foram estabelecidas as categorias, mas, pelos limites deste artigo, serão apresentadas apenas duas. Na primeira categoria, buscou-se identificar se existe, nos planos de formação docente, uma investigação do contexto em que se dá a ação educativa. Ou seja, se há informações sobre a própria equipe docente, a situação real da escola e a realidade onde vivem os estudantes e suas famílias. Uma ação considerada por Freire (2014) como ponto de partida para qualquer projeto educativo quando se pretende "estabelecer uma intimidade entre os saberes curriculares fundamentais aos alunos e a experiencia social que eles têm como indivíduos" (FREIRE, 2014, p. 32).

A segunda categoria tratou de identificar se há definição do tema gerador (Freire, 2005) dos planos de formação que considere as prioridades formativas da equipe. Os temas elencados pelas equipes e os conteúdos dos planos de formação foram objetos de análise.

\subsection{Primeira categoria: investigação da realidade}

Os resultados da análise preliminar apontaram que os Projetos Político-Pedagógicos, que abarcam os planos de formação, apresentam o histórico e os dados da instituição com uma importante avaliação do ano anterior. Há informações sobre a estrutura da escola, sua organização geral e alguns apontamentos a respeito das dificuldades enfrentadas pela equipe, inclusive em relação às condições de trabalho.

Todos os PPP expõem uma detalhada caracterização da comunidade escolar, relatando a composição do bairro, as moradias, a existência de agentes comunitários de saúde, de unidade de pronto atendimento, unidade básica de saúde, meios de transporte, saneamento básico e rede de abastecimento de água. Apresentam dados sobre igrejas, equipamentos culturais e de lazer, associações e grupos populares, dentre outras informações sobre o bairro.

Identificamos, nos documentos, avaliações das famílias que são convidadas a se manifestarem sobre a organização geral da escola e o trabalho pedagógico. As avaliações foram consideradas na definição de ações e encaminhamentos, para a melhoria das condições pedagógicas, que incluem adequações administrativas, estruturais e materiais. No PF2, os estudantes também foram ouvidos e suas manifestações constam no PPP, demonstrando que a equipe escolar de fato considera a efetiva participação deles e de suas famílias.

Quanto às informações sobre a equipe docente, em todos os documentos há um quadro com o nome de cada profissional da escola, cargo, formação acadêmica e horário de trabalho.

No PF5 existem outros dados que foram coletados por meio de questionários, onde constam a formação acadêmica dos docentes, os cursos que concluíram, o tempo de experiência, suas considerações sobre o processo de ensino e aprendizagem, dentre outras informações. Ressaltamos a relevância desse plano pela importância de conhecer a equipe docente, com dados organizados e sistematizados.

Os elementos constantes nos PPP podem indicar que as padronizações propostas na BNCC sejam objeto de críticas pelas equipes docentes, uma vez que a educação integral assumida nas oito escolas não estimula competição, eficiência e meritocracia. A investigação sobre dados da realidade e dos sujeitos está presente em todos os planos, evidenciando uma concepção de educação que leva em conta os sujeitos em situação. 
Constatamos, no entanto, que é preciso avançar na elaboração dos planos de formação docente, explicitando a relação entre os dados coletados, o currículo e as ações pedagógicas. Essa desarticulação tornou-se evidente na segunda categoria analisada.

\subsection{Segunda categoria: tema gerador e sua problematização}

Constatamos, nos planos de formação, a dificuldade em se estabelecer prioridades para o processo formativo dos docentes. Os encontros semanais servem a diferentes propósitos, desde a transmissão de recados e informes, até planejamentos de demandas não previstas. Conforme afirmamos, a interferência externa na organização escolar sobrepõe-se ao Projeto Político-Pedagógico, além de provocar sobrecarga de trabalho. Há muitos conteúdos sendo discutidos com a equipe docente nesses encontros semanais, alguns deles definidos a partir das diretrizes da Secretaria de Educação, além de demandas burocráticas. A BNCC, na área de Ciências Humanas, consta como conteúdo em todos os planos, cuja formação está sob a coordenação da própria Secretaria de Educação, no formato EaD. Os docentes têm acesso pelo Ambiente Virtual de Aprendizagem AVA-MEC, ocupando parte do tempo destinado aos encontros coletivos. O conteúdo dessa formação não é retomado para discussão coletiva da equipe escolar, que, nos demais encontros trata de outros temas, incluindo outras áreas da BNCC, evidenciando a fragmentação do processo formativo.

Neste artigo, a apresentação das análises dos planos de formação foi organizada em três blocos, considerando pontos comuns.

O primeiro bloco se refere aos PF1, PF4, PF5 e PF7, que apresentaram poucas informações, nem sempre justificando as escolhas dos temas e conteúdos a serem tratados com os docentes.

No PF1 foi planejado o conteúdo da BNCC de Matemática, além de abordar "aprendizagem criativa" e cultura Maker, com carga horária reduzida. Não ficam explícitos os propósitos dessas escolhas. Parece-nos que a relevância da tecnologia pautada na ideia de inovação pode levar a formações aligeiradas, o que limita a reflexão dos docentes acerca das práticas pedagógicas que consideram a tecnologia na educação integral dos estudantes.

No PF4 consta apenas a informação de que a equipe é nova, o que requer apresentação da documentação escolar para esse grupo de trabalho, além de "troca de experiências" entre os docentes. É comum que as equipes gestoras assumam a responsabilidade pela formação de docentes que ingressam, muitas vezes sem experiência, optando por estratégias consideradas mais eficientes para uma preparação mais rápida, como as "trocas de experiências". O risco dessa opção é a carência de um consistente suporte teórico que permita compreender os propósitos e fundamentos didáticos e pedagógicos das práticas.

No PF7 propõe-se o estudo à distância da BNCC na área de Matemática, sendo que os encontros presenciais são previstos para planejamento de aulas e de eventos coletivos. Não ficam explícitas as relações entre o estudo da Matemática e os planos de ensino dos docentes.

Destacamos o diferencial positivo do PF5 por oferecer informações detalhadas sobre a comunidade, a escola e os docentes, cujos dados justificaram a elaboração do plano de formação docente, mas, pela abundância de temas, organizaram encontros semanais para o "estudo de práticas", sem, contudo, apresentar fundamentos teórico-metodológicos que sustentem as análises das referidas práticas.

No segundo bloco estão os PF2 e PF6, com justificativa para os conteúdos selecionados e um posicionamento mais crítico em relação aos anteriores.

O PF2 apresenta um texto introdutório, definindo a opção pelo tema "Matemática", que é estudado e analisado a partir de programas de governos federais que assumiram em períodos anteriores, como Parâmetros Curriculares Nacionais (BRASIL, 1998), Pacto Nacional para Alfabetização na Idade Certa (BRASIL, 2012), Diretrizes Curriculares Nacionais (BRASIL, 2013) e BNCC (BRASIL, 2017). Apesar de não haver dados sobre avaliação do ensino de Matemática nessa instituição que justifique a escolha desse tema, a análise dos diversos programas, para além da BNCC, pode indicar que a equipe escolar preserva o princípio da criticidade com base em estudos de diferentes políticas e de teóricos mencionados no plano. 
O PF6 indica o tema "Matemática" como prioridade para encontros quinzenais, por terem identificado essa necessidade na formação dos docentes. A equipe propõe esse estudo com apoio do material do Pacto Nacional para Alfabetização na Idade Certa (BRASIL, 2012), um programa de outra gestão que já havia sido considerado no Projeto Político-Pedagógico.

Nessas duas escolas, a continuidade do estudo de políticas anteriores indica que não houve abandono do que já vinha sendo estudado e discutido pela equipe antes da BNCC, o que pode significar um posicionamento mais crítico. Nesses planos há indicativos de que uma política não é simplesmente substituída por outra, embora todas devam ser criticamente analisadas.

No terceiro bloco estão o PF3 e PF8, que apresentam fundamentos para a educação integral. No PF3, o texto introdutório comunica os princípios educacionais do Projeto Político-Pedagógico, ressaltando que a educação integral é assumida de forma coletiva pelos docentes e funcionários, com estratégias voltadas à organização do tempo, espaço, e inserindo no currículo temas da atualidade, como: cultura da paz, combate à violência contra a mulher e a criança, poluição ambiental, história e cultura afro-brasileira e dos povos indígenas, questões das etnias, de gênero, socioambientais, da preservação da memória do bairro e do sujeito, da apropriação de conhecimentos tecnológicos e da comunicação. Esses temas, presentes no currículo da escola, indicam autonomia em relação à BNCC, que não é assumida por essa equipe sem reflexão e não se limita aos conteúdos fragmentados. Nesse plano, ressalta-se a gestão democrática da escola, que também consta como conteúdo a ser tratado com a equipe docente.

Finalizando nossas análises, destacamos o PF8, que demonstra um plano de formação bastante consistente, explicitando as finalidades da escola e estabelecendo objetivos claros e articulados para a formação docente.

No PF8 encontramos a caracterização da equipe escolar e a justificativa para os encontros coletivos, com foco na educação integral para repensar o currículo, proposta pedagógica e projetos educativos, impulsionando a construção de um percurso formativo necessário para a qualificação da educação. De acordo com o documento, nesse processo formativo se assume uma educação que oportunize o desenvolvimento do sujeito em todas as suas dimensões - intelectual, física, emocional, social e cultural -, reconhecendo as interações coletivas no trabalho pedagógico. $\mathrm{Na}$ definição dos objetivos do plano formativo, constam o aprofundamento dos estudos relativos ao conceito de educação integral; planejamento coletivo de propostas pedagógicas voltadas às múltiplas possibilidades de aprendizagem por meio do acesso à cultura, arte, esporte, ciência e tecnologia; reelaboração do currículo, tendo em mente a educação integral dos estudantes em todas as suas dimensões; articulação dos diferentes tempos e espaços de aprendizagens, considerando a diversidade; recriação de rotinas, tendo em vista as relações entre as pessoas e o conhecimento, promovendo análises das avaliações na construção do currículo.

O PF8 aprofunda o tema "educação integral", definindo conteúdos necessários ao estudo desse tema. Nesse documento, a BNCC não é concebida como prescrição, sendo importante o estudo coletivo para estabelecer possíveis relações com o PPP que vem sendo elaborado pela equipe. A análise desse plano indica possibilidades na formação crítica e emancipada de docentes e estudantes.

\section{Considerações finais}

A despeito das críticas acerca do caráter tecnicista e regulatório da política do governo federal com a publicação da BNCC, sua implementação vem ocorrendo em todo o País, impactando nos encontros formativos que ocorrem no âmbito das unidades escolares.

Com a epistemologia do ciclo de políticas conclui-se que, ao mesmo tempo em que se submetem às diretrizes impostas, as equipes escolares podem conquistar, no contexto da prática, algum nível de autonomia, vivendo contradições difíceis, mas que indicam possibilidades de avanços em relação à formação humanista e democrática. Tais possibilidades ficaram explícitas no plano formativo de duas escolas e se mostraram mais limitadas nas outras seis. 
Apesar da tentativa de implementação dos pressupostos ideológicos da BNCC, identificamos, especialmente nos documentos de duas escolas, conteúdos voltados à educação integral que valorizam os saberes, as experiências e culturas dos estudantes e docentes. Estão previstas estratégias para intensificar a participação das famílias e dos estudantes em conselhos mirins e assembleias escolares, e também outras ações que indicam relações pedagógicas mais democráticas.

A epistemologia do ciclo de políticas permitiu constatar que, no contexto da prática, as políticas podem ser reinterpretadas e recriadas, apontando, inclusive, posições contra-hegemônicas.

Com o embasamento teórico de Paulo Freire, conclui-se que a formação em serviço é um espaço de disputas e resistências, cabendo à escola sustentar "o poder burguês", ao mesmo tempo em que pode "desopacizar a realidade enevoada pela ideologia dominante". Para isso, "a claridade política é indispensável, necessária, mas não suficiente", e um dos obstáculos é a própria "incoerência dos educadores" (Freire, 2001, p. 29).

Essa incoerência, a que se refere Freire, e que constatamos em alguns dos planos analisados, é também fruto de um processo formativo prescritivo e regulatório, de políticas educacionais que são alteradas conforme a ideologia dos diferentes governos que assumem o poder, das difíceis condições de trabalho, dentre outros fatores que dificultam a compreensão da realidade.

Freire aponta caminhos, argumentando que somos sujeitos condicionados, mas não determinados, reconhecendo em cada pessoa sua capacidade crítica de "compreender, de inteligir o mundo, de nele intervir técnica, ética, estética, científica e politicamente" (Freire, 2001, p. 9). Além disso, as escolas podem ser espaços coletivos de resistência e de ressignificação das políticas, uma vez que o processo de profissionalização é uma construção social e histórica, viabilizando posicionamentos contrarregulatórios.

A formação docente não se encerra no âmbito dos programas elaborados pelas redes de ensino ou pelas escolas. No contexto da pandemia, vêm sendo formados coletivos de educadores como importantes instâncias de resistência contra a realidade opressora. Com o recurso da internet, abrem-se espaços de participação em eventos diversos no campo da educação, da cultura, da política, potencializando o diálogo problematizador com outros educadores e pesquisadores para a ampliação da leitura crítica da realidade. São possibilidades coletivas de educação permanente, que favorecem "a constatação das incoerências" para a superação que "é, em si, já, um exercício ético" (Freire, 2001, p. 22). Assim, "quanto mais inserido nessa realidade que o coloca em situação e quanto mais debruçar-se reflexivamente sobre a situacionalidade, mais [o docente] se tornará sujeito se afirmando como um ser de opções" (Freire, 1974, p. 12, grifos do autor).

Concluímos que os projetos de formação docente precisam avançar em relação a uma concepção educativa que reconheça a participação da equipe docente na investigação da realidade, na definição do tema prioritário e no planejamento teórico-metodológico para a preparação da própria equipe, o que significa conceber uma formação com os/as professores/as e não para os professores/as.

Compreender os condicionantes políticos, sociais, econômicos e culturais que atingem a sociedade e a educação é premissa para a construção de outro olhar no processo de formação e profissionalização dos docentes, reconhecendo a possibilidade de "reinventar o mundo numa direção ética e estética mais além dos padrões que aí estão" (Freire, 2001, p. 19). Os pressupostos teóricos de Freire nos oferecem a base filosófica e epistemológica para uma formação "desveladora", "desocultadora", "iluminadora das tramas sociais e históricas" (Freire, 2001, p. 23). Uma formação rigorosamente crítica e transformadora, para a gradativa construção da práxis docente, é uma mensagem de esperança. 


\section{Referências}

Adrião, T., Marques, L. R. \& Aguiar, M. A. da S. (Orgs.) (2019). Políticas e prioridades para educação básica dos governos estaduais eleitos em 2018: para onde os sistemas estaduais caminham? Livro do GT5 Estado e Política Educacional. Anpae.

Agência IBGE (2020, julho). PNAD educação 2019: mais da metade das pessoas de 25 anos ou mais não completaram o ensino médio. https://agenciadenoticias.ibge.gov.br/agencia-sala-de-imprensa/2013-agenciade-noticias/releases/28285-pnad-educacao-2019-mais-da-metade-das-pessoas-de-25-anos-ou-mais-naocompletaram-o-ensino-medio

Arroyo, M. (2000, janeiro). Fracasso/sucesso: um pesadelo que perturba nossos sonhos. Em Aberto, 17(71), 33-40. http://dx.doi.org/10.24109/2176-6673.emaberto.17i71.2100

Associação Nacional de Pós-Graduação e Pesquisa em Educação. (2017, abril). Nota da Anped sobre entrega da terceira versão da Base Nacional Comum Curricular (BNCC) ao Conselho Nacional de Educação (CNE). https://www.anped.org.br/sites/default/files/nota_da_anped_sobre_a_entrega_da_terceira_versao_d a_base_nacional_comum_curricular_abril_2017.pdf

Associação Nacional pela Formação dos Profissionais da Educação. (2017, 11 de setembro). Posição da ANFOPE sobre a BNCC. http://www.anfope.org.br/wp-content/uploads/2018/05/CARTA-deBrasilia_ANFOPE-V-Audiencia-Publica-CNE.-11.9.2017.pdf

Ball, S. J., Maguire, M., \& Braun, A. (2016). Como as escolas faz̧em as políticas: atuação em escolas secundárias. Trad.: Janete Bridon. Editora UEPG, 332p.

Benavente, A. (2011). Educação, um campo de luta ideológica e polititica. Observatório das políticas de educação e formação. Portugal: CES.US.CeiED. ULHT. http://www.op-edu.eu/artigo/educacao-um-campo-deluta-ideologica-e-politica.

Brasil. Ministério da Educação (1998). Parâmetros Curriculares Nacionais. http://portal.mec.gov.br/pnld/195-secretarias-112877938/seb-educacao-basica-2007048997/12640parametros-curriculares-nacionais-1o-a-4o-series

Brasil. Ministério da Educação (2012). Pacto Nacional para Alfabetização na Idade Certa.

Brasil. Ministério da Educação (2013). Diretrizes Curriculares Nacionais para a Educação Básica. http://portal.mec.gov.br/docman/julho-2013-pdf/13677-diretrizes-educacao-basica-2013-pdf/file

Brasil. Ministério da Educação. (2011). Programa Mais Educação: passo a passo.

http://educacaointegral.mec.gov.br/images/pdf/bibioteca/11_passo_passo_mais_educacao_seb.pdf

Brasil. Ministério da Educação. (2014). Caderno Territórios Educativos para Educação Integral. https://educacaointegral.org.br/wp-content/uploads/2014/04/territorioseducativos.pdf

Brasil. Ministério da Educação. (2017, novembro). Base Nacional Comum Curricular - versão aprovada pelo CNE. http://basenacionalcomum.mec.gov.br/images/BNCC_EI_EF_110518_versaofinal_site.pdf 
Brasil. Ministério da Educação. (2019). Conselho Nacional de Educação. Diretriżes Curriculares Nacionais e Base Nacional Comum para a Formação Inicial e Continuada de Professores da Educaşão Básica. Versão preliminar publicada em 18 set. 2019.

Brasil. Ministério da Educação. Instituto Nacional de Estudos e Pesquisas Educacionais Anísio Teixeira (2020). Indicadores educacionais. https://www.gov.br/inep/pt-br/acesso-a-informacao/dadosabertos/indicadores-educacionais

Brasil. Presidência da República (1996). Lei n. 9.394 Estabelece as diretrizes e bases da educação nacional.

Campanha Nacional pelo Direito à Educação. (2020). VII Balanço do Plano Nacional de Educação. Semana de Ação Mundial 2020.

https://media.campanha.org.br/semanadeacaomundial/2020/materiais/BALANCO_14052020.pdf

Fórum Nacional de Educação. (2017). Nota do Fórum Nacional de Educação. publicada em 10 de abril de 2017. https://anped.org.br/sites/default/files/images/nota_publica_fne_bncc_rev.pdf.pdf

Freire, P. (1974). Uma educação para a liberdade. 3a ed. Textos marginais.

Freire, P. (2001). Política e educação: ensaios. 5a ed. Cortez Editora.

Freire, P. (2005). Pedagogia do oprimido. 46a ed. Paz e Terra.

Freire, P. (2014). Pedagogia da autonomia: saberes necessários à prática educativa. 49aa ed. Paz e Terra.

Freitas, L. C. (2012, abril-junho). Os reformadores empresariais da educação: da desmoralização do magistério à destruição do sistema público de educação. Educaşão \& Sociedade, 33(119), 379-404. https://doi.org/10.1590/S0101-73302012000200004

Freitas, L. C. (2013, janeiro-abril). Políticas de responsabilização: entre a falta de evidência e a ética. Cadernos de Pesquisa, 43(148). https://doi.org/10.1590/S0100-15742013000100018

Freitas, L. C. (2014, junho). Os empresários e a política educacional: como o proclamado direito à educação de qualidade é negado na prática pelos reformadores empresariais. Germinal: Marxismo e Educação em Debate, 6(1), 48-59. http://doi.org/10.9771/gmed.v6i1.12594

Frigotto, G. (1985, setembro-dezembro). Trabalho como princípio educativo: por uma superação das ambiguidades. Boletim Técnico do SENAC, 11(3), 175-182.

Gadotti, M. (2009). Educação Integral no Brasil: inovações em processo. Editora e Livraria Instituto Paulo Freire - (Educação Cidadã; 4).

Holsti, O. R. (1969). Content analysis for the social sciences and humanities. Reading, Mass. Addison-Wesley.

http://portal.mec.gov.br/component/tags/tag/pacto-nacional-pela-alfabetizacao-na-idade-certa

Libâneo, J. C. (2019). Finalidades educativas escolares em disputa, currículo e didática. In Libâneo, J. C., Echalar, A. D. L. F., Suanno, M. V. R., Rosa, S. V. L. (orgs.). Em defesa do direito à educação escolar didática, curriculo e politicas educacionais em debate. VII Edipe. Editora da UFG. 
Lüdke, M., \& André, M.E.D.A (2015). Pesquisa em educação: abordagens qualitativas. 2a ed. Rio de Janeiro: E.P.U.

Mainardes, J. (2006, janeiro-abril). Organização da escolaridade em ciclos no Brasil: revisão da literatura e perspectivas para a pesquisa. Educação e Pesquisa, 32(1), 11-30. https://doi.org/10.1590/S151797022006000100002

Maués, O. (2009). Regulação educacional, formação e trabalho docente. Revista Estudos em Avaliação Educacional - Fundação Carlos Chagas, 20(44). https://doi.org/10.18222/eae204420092040

Schön, D. (1991). The reflective practicioner: how professionals think in action. Temple Smith.

\section{Sobre a Autora}

\section{ELISABETE FERREIRA ESTEVES CAMPOS}

(iD) ORCID: https://orcid.org/0000-0002-2023-0714

Doutora em Educação pela Universidade de São Paulo-USP. Docente e pesquisadora do Programa de Pós-Graduação Stricto Sensu em Educação da Universidade Metodista de São Paulo. Líder do Grupo de Pesquisa "Políticas de Gestão Educacional e de Formação dos Profissionais de Educação" e do Grupo de Estudos Paulo Freire (UMESP).

E-mail: betecampos@terra.com.br; elisabete.campos@metodista.br.

Enviado em: 16 dez. 2020.

Aprovado em: 4 mar. 2021. 